\title{
Acoustic test facility at Tianjin spacecraft AIT center of China
}

\author{
Xinming Li ${ }^{1}$, Wenbing Zhang' ${ }^{2}$, Guiqian Fang ${ }^{3}$, Jungang Zhang ${ }^{4}$ \\ Beijing Institute of Spacecraft Environment Engineering, Beijing, China \\ National Key Laboratory of Science and Technology on Reliability and Environment Engineering, Beijing, \\ China \\ ${ }^{1}$ Corresponding author \\ E-mail: ${ }^{1}$ cast_lee@aliyun.com, ${ }^{2}$ zhang_wb@126.com, ${ }^{3}$ fanggq511@126.com, ${ }^{4}$ zhangfu445@sohu.com
}

Received 1 September 2018; accepted 16 September 2018

DOI https://doi.org/10.21595/vp.2018.20218

Check for updates

Copyright (C) 2018 Xinming Li, et al. This is an open access article distributed under the Creative Commons Attribution License, which permits unrestricted use, distribution, and reproduction in any medium, provided the original work is properly cited.

\begin{abstract}
The China Academy of Space Technology (CAST) designs and builds a new world-class Assembly, Integration and Test Center (AITC) at Tianjin, China. Modal, vibration and acoustic test facilities are built to support the future environmental testing needs of China space station program. The Reverberation Acoustic Test Facility (RATF) is about $4000 \mathrm{~m}^{3}$ in volume and can achieved an empty chamber acoustic overall sound pressure level (OASPL) higher than $156 \mathrm{~dB}$. It is the largest acoustic facility in Asia. Beijing Institute of spacecraft Environment Engineering (BISEE) started its design and construction work from 2012 and put it into use at October of 2015. The RATF will provide an efficient support for environment testing needs of China and world's space program in the future.
\end{abstract}

Keywords: AITC, RATF, $4000 \mathrm{~m}^{3}$, BISEE.

\section{Introduction}

The China Academy of Space Technology (CAST) is tasked to develop new Assembly, Integration and Test Center (AITC) to support the developing of space station program (the model is shown as Fig. 1), lunar exploration program and etc. In the AITC, there is world's largest electric shaker $(1400 \mathrm{kN})$, and the Chinese largest thermal vacuum chamber and reverberation acoustic chamber. A picture on the AITC after construction is shown as Fig. 2. The Beijing Institute of spacecraft Environment Engineering (BISEE) gets the contract to design and construct these systems.

The Reverberation Acoustic Test Facility (RATF) is about $4000 \mathrm{~m}^{3}$ in volume and can achieved an empty chamber acoustic overall sound pressure level (OASPL) higher than $156 \mathrm{~dB}$.

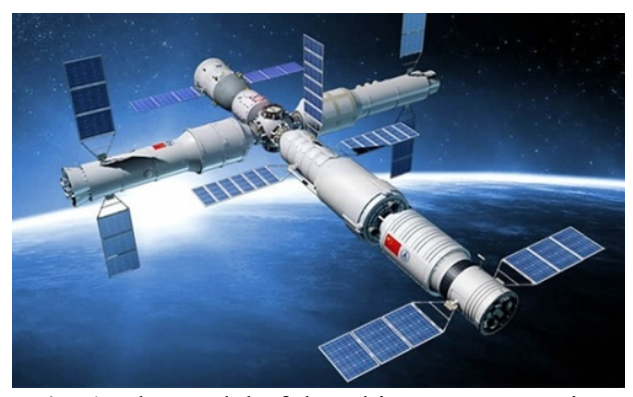

Fig. 1. The model of the Chinese space station

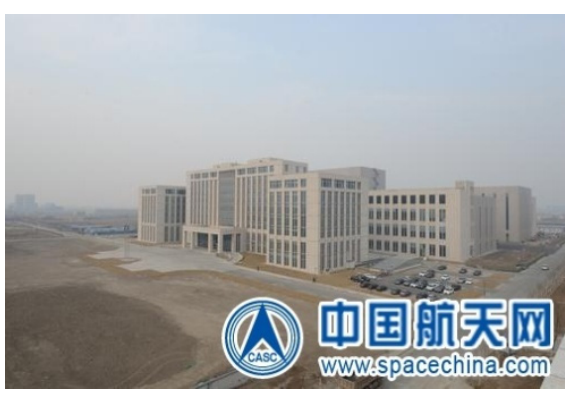

Fig. 2. The new AITC of CAST

\section{Specifications}

The RATF's test chamber shall physically allow a $7.5 \mathrm{~m}$ diameter and $18.5 \mathrm{~m}$ tall test specimen, and its weight is up to 30 ton.

The typical acoustic test spectrums of the existing launchers in China are shown as Fig. 3. 


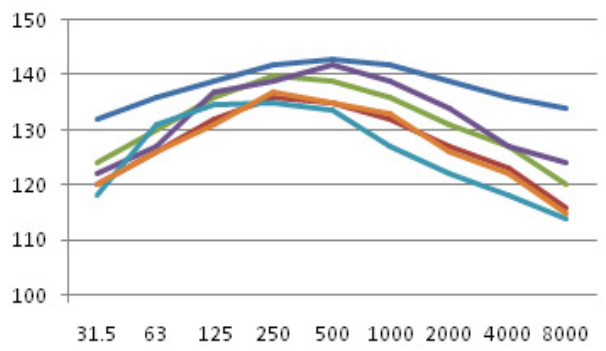

Fig. 3. Acoustic test spectrum requirements for RATF

Spatial homogeneity: better than $\pm 1 \mathrm{~dB}$ in the test volume.

\section{Design and construction}

\subsection{Configuration}

RATF usually composes of building, sound generation system, gas generation system, and control system. Fig. 4 shows the principle of acoustic test. Specimen is placed in the middle of the chamber and then the sound generation system generates high level sound pressure field. The specimen is excited and its performance in acoustic environment is verified.

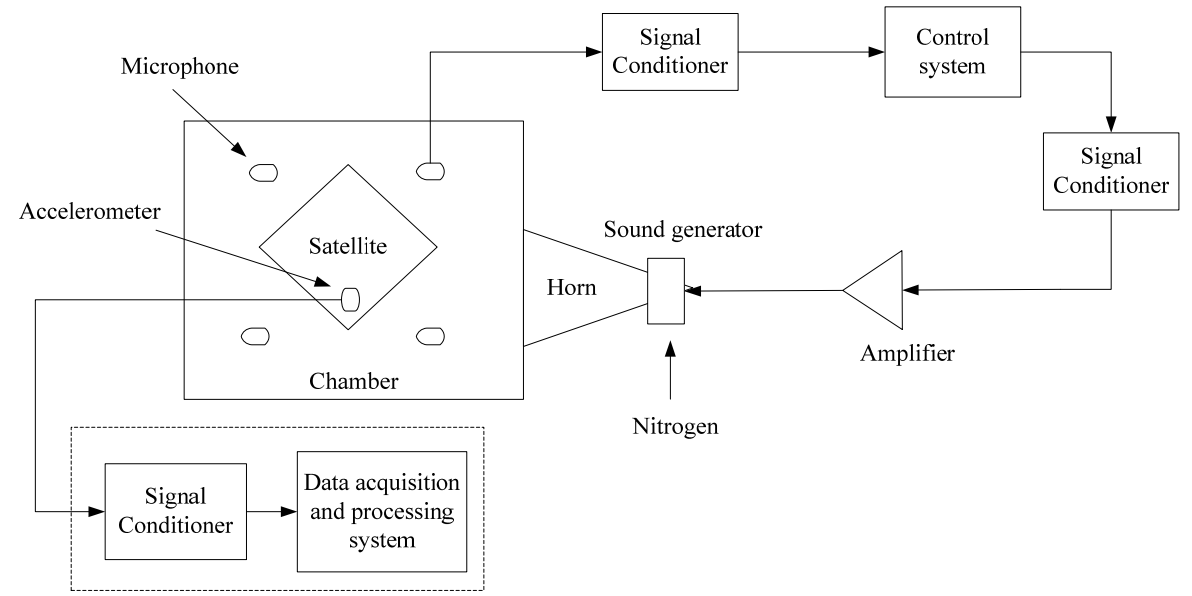

Fig. 4. Principle of acoustic test

\subsection{Buildings}

In reference with above-mentioned specification, the useful dimensions of the facility: $14.5 \mathrm{~m}$ (Length) $\times 11.5 \mathrm{~m}($ Width $) \times 24 \mathrm{~m}$ (Height). These dimensions offer a sufficient number of modes in the low frequency domain ( 7 modes in the first $1 / 3$ octave) and a useful test volume $4000 \mathrm{~m}^{3}$.

The wall and envelop is $0.7 \mathrm{~m}$ in thickness. Horns rooms located at the west and north sides, and the anechoic tunnel is on the top of the chamber.

A sliding door resulting in a useful $10 \mathrm{~m} \times 22 \mathrm{~m}$ entrance (the mass of the door is roughly 200 tons). The door moving on two rails, and the guiding system used for the slide door will be based on a rolling cylinder system. Fig. 5 displays the install process of the door. There is a vertical hinged man door at the sliding door.

\subsection{Sound generation system}

The functional specification related to acoustic performance $(156 \mathrm{~dB})$ has led to the noise 
configuration: 2 LF-60 modulators (Provided by SEREME), 6 EPT-200 modulators and 10 modulators made in China. The modulators connected to exponential horns: $20 \mathrm{~Hz}$ (2), $40 \mathrm{~Hz}(2)$, $80 \mathrm{~Hz}(2), 100 \mathrm{~Hz}(2), 160 \mathrm{~Hz}(5)$ and $200 \mathrm{~Hz}$ (7). These horns were installed in the west and north wall of the RATF, shown as Fig. 6.

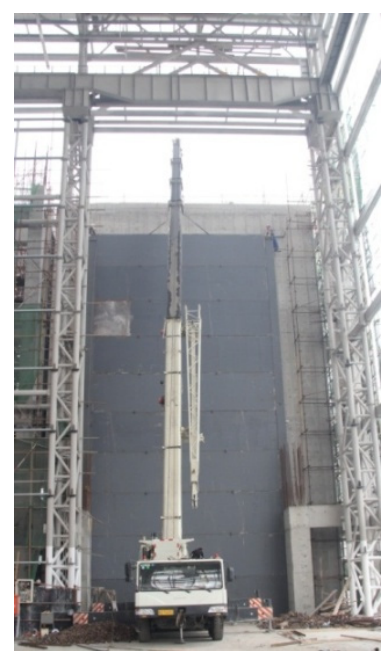

Fig. 5. Construction photo of the door

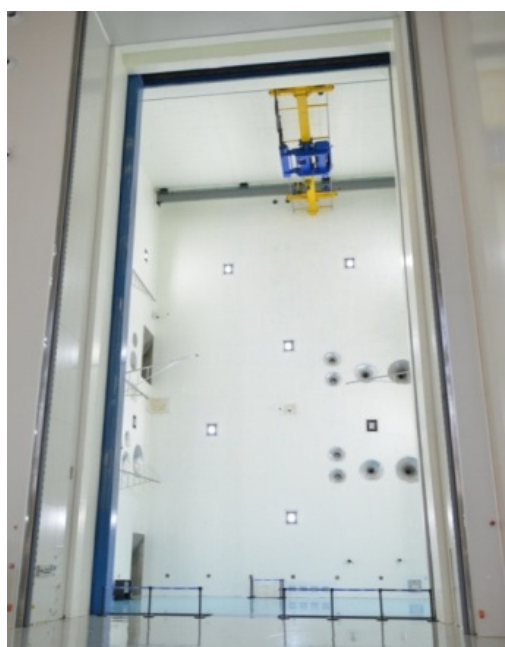

Fig. 6. $4000 \mathrm{~m}^{3}$ acoustic chamber

\subsection{Gas generation system}

The sound system configuration described here-above, induces the following specification on the gas flow (gaseous nitrogen):

1) Maximum flow rate: $800 \mathrm{Nm}^{3} / \mathrm{min}$;

2) Gas pressure (absolute): $2.5 \pm 0.1$ Bar.

In addition, the system should allow 10 acoustic runs per day at maximum flow rate, and each duration is 3 minutes. Fig. 7 shows the overall principle of the gas generation system.

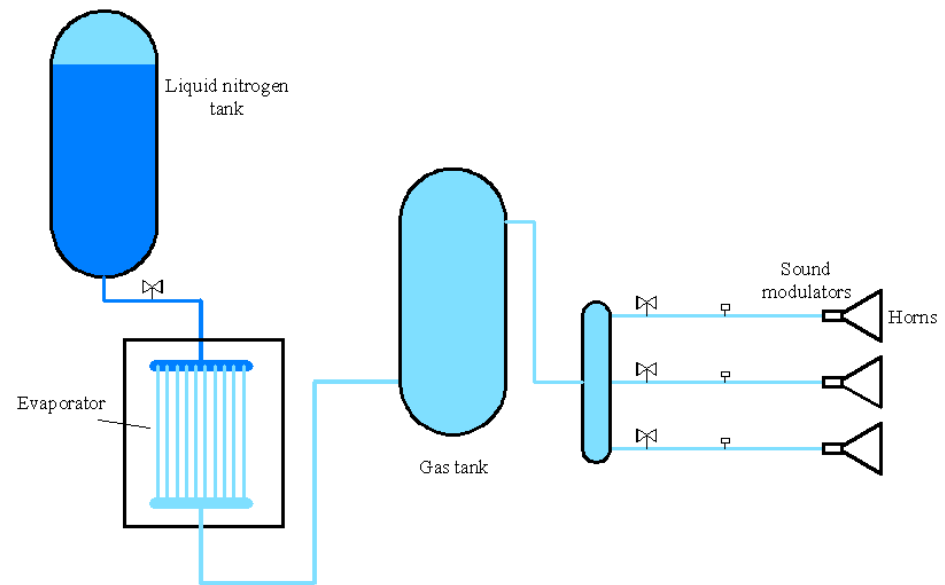

Fig. 7. Principle of gas generation system

Liquid nitrogen stored in two $30 \mathrm{~m}^{3}$ tanks at 16bar. Two evaporators installed in a pool $(11 \mathrm{~m} \times 7.5 \mathrm{~m} \times 4 \mathrm{~m})$ filled with water.

Two $30 \mathrm{~m}^{3}$ gas tanks were used to store the nitrogen gas, and reduce the fluctuation of pressure. A picture of the tanks is shown as Fig. 8. 
Independent and controlled inlet is designed for each modulator by using electric valves and pressure transmitters.

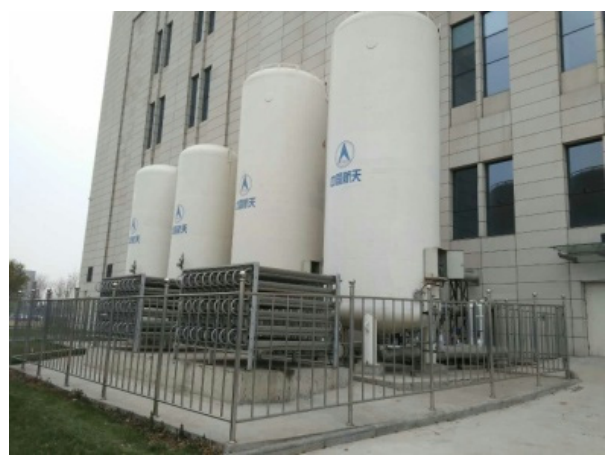

Fig. 8. Photo of tanks

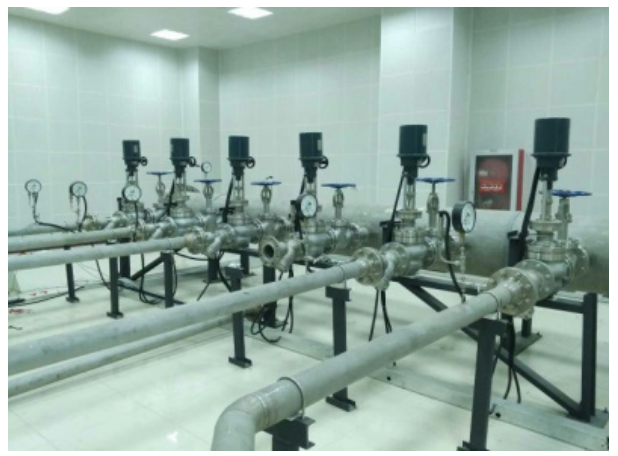

Fig. 9. Pipelines and valves

\subsection{Control system}

Gas generation system: the control of the gas is obtained using PLC (Programmable Logic Controller), and the operator can control the pressure and flow rate at computer.

Acoustic control system: An automatic system is developed by BISEE, and it can offer a credible and efficient close loop control of acoustic test. The interface of the control software is shown as Fig. 10.

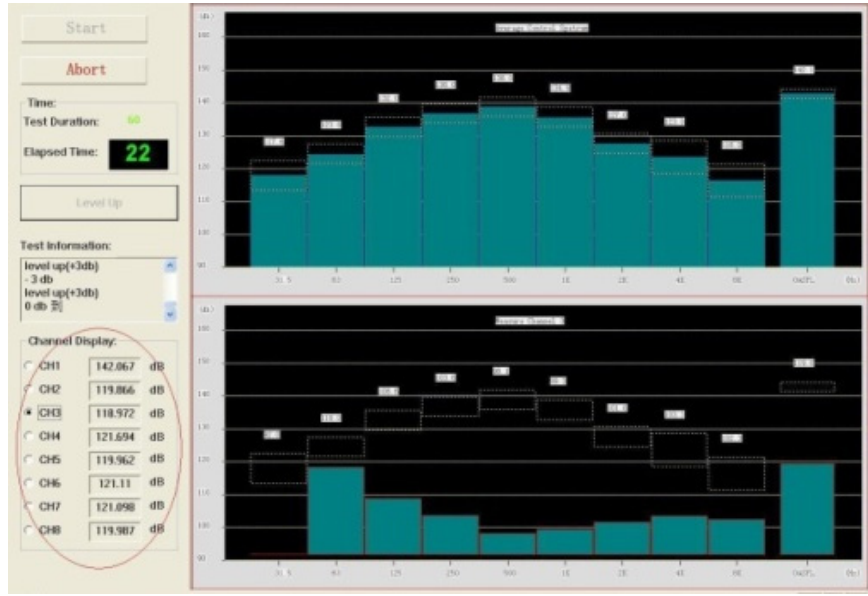

Fig. 10. Interface of the acoustic control system 


\section{Test and use}

The RATF was put into use at October 2015 after acceptance tests. It was used to perform an Acoustic Fill effect test and analysis of Spacecraft, shown as Fig. 11. The result obtained enabled BISEE to define an implementation methodology and incorporate it into the ISO standard.

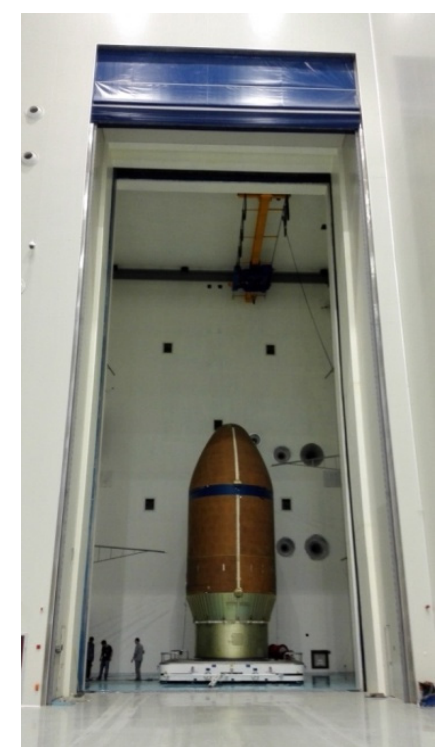

Fig. 11. Photo taken during acoustic fill effect test

\section{Conclusions}

BISEE designed and constructed a new big RATF for CAST. It offers $4000 \mathrm{~m}^{3}$ useful test volume and a sufficient number of modes from the first $1 / 3$ octave $(25 \mathrm{~Hz})$. The entrance is $10 \mathrm{~m} \times 22 \mathrm{~m}$, and the OASPL is higher than $156 \mathrm{~dB}$. The RATF will provide an efficient support for environment testing needs of China and world's space program in the future.

\section{References}

[1] Xiang X. H. The Test Technology of Spacecraft Mechanics Environments. China Science and Technology Press, 2010.

[2] Anant Grewal High intensity noise generation for extremely large reverberant room test applications. Proceedings of the 29th IMAC, Jacksonville, USA, 2011.

[3] Alain Meurat, Laurent Jezequel A new acoustic test facility at alcatel space test center. Proceedings of the 5th International Symposium on Environmental Testing for Space Programmes, Noordwijk, The Netherlands, 2004. 